\title{
Appendicular endometriosis: a case report
}

\author{
Priyanka Bagdi, Niranjani S.*
}

Department of Obstetrics and Gynaecology, Bharath Institute of Higher Education and Research, Shree Balaji Medical College and Hospital, Chennai, Chromepet, Tamil Nadu, India

Received: 01 December 2020

Accepted: 05 January 2021

\section{*Correspondence:}

Dr.Niranjani S.,

E-mail: nira_sms@yahoo.co.in

Copyright: (c) the author(s), publisher and licensee Medip Academy. This is an open-access article distributed under the terms of the Creative Commons Attribution Non-Commercial License, which permits unrestricted non-commercial use, distribution, and reproduction in any medium, provided the original work is properly cited.

\begin{abstract}
Endometriosis is an estrogen-dependent inflammatory disease that affects 8 to $10 \%$ of women at reproductive age, characterized by the presence of endometrial glands and stroma outside the uterine cavity. In our case we are presenting a case report of a reproductive age group woman with appendicular endometriosis, because of the presence of pelvic endometriosis combined with an enlarged appendix, the choice was appendectomy, with complete suppression of abdominal symptoms after the surgery, a fact also reported by other authors. We concluded that endometriosis of the appendix is rare and almost never diagnosed before the surgery, with the definitive diagnosis obtained through microscopic examination. However, it should always be taken into account for the diagnosis of chronic pelvic pain, especially in young women complaining of recurrent pain, history of infertility and pelvic endometriosis.
\end{abstract}

Keywords: Endometriosis, Appendix, Chronic pelvic pain, Powder burn, Gun-shot lesions

\section{INTRODUCTION}

Endometriosis is an estrogen-dependent inflammatory disease that affects 8 to $10 \%$ of women at reproductive age, characterized by the presence of endometrial glands and stroma outside the uterine cavity. ${ }^{1}$ It is most commonly found in the pouch of douglas peritoneum and the ovaries. It is seen in $12-30 \%$ of women with chronic pelvic pain and almost $50 \%$ of women with infertility. It affects the gastrointestinal tract (GIT) around $12 \%$ of the cases of which $72 \%$ occur in recto sigmoid region, $13 \%$ in recto vaginal septum, $7 \%$ in small bowel, $4 \%$ in caecum and $3 \%$ in appendix. ${ }^{2}$

Appendicular endometriosis (AE) may present as acute or chronic appendicitis, cyclical right iliac fossa pain, lower gastrointestinal (GI) bleeding, intestinal perforation, or intestinal obstruction as a result of intussusception or mucocele of appendix. ${ }^{3}$

In cases of appendix involvement, intraoperative inspection may not show any alteration that suggests endometriosis. Then, the definitive diagnosis is confirmed through histopathological analysis.

This study reports a rare case of appendiceal endometriosis in a woman with dysmenorrhoea.

\section{CASE REPORT}

A 38 years old female patient, with history of dysmenorrhoea and dyspareunia for four months. She came to our service with severe pain in suprapubic region and right iliac fossa for last five days.

On examination, she had normal vital signs, no fever, flat abdomen, presence of bowel sounds, tenderness in suprapubic region and right iliac fossa and absence of peritoneal signs.

At vaginal examination, the patient had retroverted normal size uterus, intense pain at uterine mobilization and on palpation of posterior and right lateral cul-de-sac; nonpalpable attachments. She was submitted to abdominal 
ultrasound, which showed Right ovarian endometrioma of size $7 \times 5 \mathrm{~cm}$ normal size of the uterus, with minimal free fluid in the cavity.

The treatment choice was hospitalization and plan was exploratory laparotomy with ovarian cystectomy. Intra OP findings were dense adhesions in between posterior surface of uterus and bowel. Grade 1 endometriotic spots were seen in peritoneum. Peritoneal endometriotic lesions seen. Right ovarian endometrioma measuring around 8x6 $\mathrm{cm}$ in diameter fixed to the lateral wall of the uterus. Nodules noted at the tip of appendix involving the seromuscular layer and adherent to surrounding bowel loops careful dissection of appendix and was tried and proceeded with appendicectomy and the samples were sent for histopathological examination.

Post-operative period was uneventful and was discharged from the hospital on fourth day after surgery. The histopathological examination showed impression of endometrioma of left ovary and appendicular endometriosis.

\section{DISCUSSION}

Endometriosis is defined as the presence of endometrial like tissue outside the uterus, which includes chronic, inflammatory reaction. ${ }^{4}$ The associated symptoms can impact on general physical, mental and social wellbeing.

Women in reproductive age group with dysmenorrhoea with pelvic pain or infertility, a high prevalence of endometriosis (from a low $20 \%$ to a high of $90 \%$ ) is reported.$^{5}$ In women with unexplained infertility (regular menstrual cycle, normal pelvic imaging, normospermic partner) with or without pain, the prevalence of endometriosis is reported to be as high as $50 \%$. In asymptomatic women undergoing tubal ligation (women of proven fertility), the prevalence of endometriosis ranges from $3 \%$ to $43 \%{ }^{6}$

The extent of the disease varies from a few, small lesions to large, ovarian endometriotic cysts. There can be extensive fibrosis in structures such as the uterosacral ligaments and adhesions causing marked distortion of pelvic anatomy.

\section{Endometriosis typically appears as: ${ }^{19}$}

Superficial 'powder-burn' or 'gunshot' lesions on the ovaries, serosal surfaces and peritoneum. Black, darkbrown or bluish lesions, nodules or small cysts containing old haemorrhage surrounded by a variable extent of fibrosis. Atypical or 'subtle' lesions, including red implants (petechial, vesicular, red flame like) and serous or clear vesicles. White plaques or scarring and yellowbrown peritoneal discoloration of the peritoneum. Endometriomas containing thick chocolate fluid often adherent to the peritoneum of the ovarian fossa and the surrounding fibrosis may involve the tubes and bowel.
AE frequently involves tip and body of the appendix. The layers of appendix most commonly affected are muscular and seromuscular ( $\sim 2 / 3$ rd cases), followed by the serosa ( 1/3rd cases).

\section{Types of endometriosis}

There are three main types of endometriosis, based on where it is:

\section{Superficial peritoneal lesion}

This is the most common kind. You have lesions on your peritoneum, a thin film that lines your pelvic cavity.

\section{Endometrioma (ovarian lesion)}

These dark, fluid-filled cysts, also called chocolate cysts, form deep in your ovaries. They don't respond well to treatment and can damage healthy tissue.

\section{Deeply infiltrating endometriosis}

This type grows under your peritoneum and can involve organs near your uterus, such as your bowels or bladder. About $1 \%$ to $5 \%$ of women with endometriosis have it.

Therefore, the appendix is an important organ in the evaluation of non-diagnosed chronic pelvic pain. However, only $41 \%$ of the patients with appendiceal endometriosis complain of intermittent pain in the right lower quadrant, which may or may not be related to menstruation.

Preoperative diagnosis of appendiceal endometriosis is not common. It is frequently found during the surgical treatment for pelvic endometriosis, similar to our case reported.

The definitive diagnosis is obtained through the histopathological study. Endometriosis was not the preoperative suspicion, and it was diagnosed through the histopathological study.

Some authors justify the prescription of appendectomy to patients with chronic abdominal pain with undefined origin, even when the organ aspect is normal. Whereas some authors favor organ resection when it is rigid as a result of deep infiltrating endometriosis as they can result in mucocele of appendix. The same author does not indicate prophylactic appendectomy to all patients submitted to laparoscopy due to chronic abdominal pain given the low probability of endometriosis in this organ.

In our case, because of the presence of pelvic endometriosis combined with an enlarged appendix, the choice was appendectomy, with complete suppression of abdominal symptoms after the surgery, a fact also reported by other authors. 


\section{CONCLUSION}

We concluded that endometriosis of the appendix is rare and almost never diagnosed before the surgery, with the definitive diagnosis obtained through microscopic exam. However, it should always be taken into account for the diagnosis of chronic pelvic pain, especially in young women complaining of recurrent pain, history of infertility and pelvic endometriosis.

\section{Funding: No funding sources}

Conflict of interest: None declared

Ethical approval: Not required

\section{REFERENCES}

1. Bulun SE. Endometriosis. N Engl J Med. 2009;360(3):268-79.

2. Podgaec S, Gonçalves MO, Klajner S, Abrão MS. Epigastric pain relating to menses can be a symptom of bowel endometriosis. Sao Paulo Med J. 2008;126(4):242-4

3. Khoo JJ, Ismail MS, Tiu CC. Endometriosis of the appendix presenting as acute appendicitis. Singapore Med J. 2004;45(9):435-6.

4. Hasegawa T, Yoshida K, Matsui K. Endometriosis of the Appendix Resulting in Perforated Appendicitis. Case Rep Gastroenterol. 2007;1(1):27-31.

5. Ijaz S, Lidder S, Mohamid W, Carter M, Thompson $\mathrm{H}$. Intussusception of the appendix secondary to endometriosis: a case report. J Med Case Reports. 2008;2:12.

6. Krairy GA. Endometriosis of the appendix: a trap for the urwary. Saudi J Gastroenterol. 2005;11(1):45-7.

7. Tumay V, Ozturk E, Ozturk H, Yilmazlar T. Appendiceal endometriosis mimicking acute appendicitis. Acta Chir Belg. 2006;106(6):712-3.

8. Gustofson RL, Kim N, Liu S, Stratton P. Endometriosis and the appendix: a case series and comprehensive review of the literature. FertilSteril. 2006;86(2):298-303.

9. Al Oulaqi NS, Hefny AF, Joshi S, Salim K, AbuZidan FM. Endometriosis of the Appendix. Afr Health Sci. 2008;8(3):196-8.
10. DrimanDKm, Melega DE, Vilos GA, Plewes EA. Mucocele of the appendix secondary to endometriosis. Report of two cases, one with localized pseudomyxoma peritonei. Am J Clin Pathol. 2000;113(6):860-4.

11. Tez M, Akgül O, Ertan T, Göçmen E, Bilgin A, Han O. Endometriosis of the appendix. Turk $\mathbf{J}$ Gastroenterol. 2006;17(3):250-1.

12. Sagae EU, Lopasso F, Abrão MS, Cavalli N, Rodrigues JJG. Endometriose do tratogastrintestinal correlaçõesclínicas e laparoscópicas. Rev bras Coloproct. 2007;27(4):423-31.

13. Chang-Hun L, Dong-Hoon S, Jun-Woo L. Obstructive mucocele of the appendix secondary to endometriosis - a case report. Korean J Pathol. 2004;38(6):419-22.

14. Flores I, Abreu S, Abac S, Fourquet J, Laboy J, RíosBedoya C. Self-reported prevalence of endometriosis and its symptoms among Puerto Rican women. Int $\mathbf{J}$ Gynaecol Obstet. 2008;100(3):257-61.

15. Nisolle M, Pasleau F, Foidart JM. Extragenital endometriosis. J Gynecol Obstet Biol Reprod (Paris). 2007;36(2):173-8.

16. Snyder TE, Selanders JR. Incidental appendectomy yes or no? A retrospective case study and review of the literature. Infect Dis Obstet Gynecol. 1998;6(1):30-7.

17. Jones AE, Phillips AW, Jarvis JR, Sargen K. The value of routine histopathological examination of appendicectomy specimens. BMC Surg. 2007;7:17.

18. Stegmann BJ, Sinaii N, Liu S, Segars J, Merino M, Nieman LK, et al. Using location, color, size, and depth to characterize and identify endometriosis lesions in a cohort of 133 women. Fertil Steril. 2008;89(6):1632-6.

19. Green Top Guidelines No. 2006. Available at: https://www.rcog.org.uk/en/guidelines-researchservices/guidelines/gtg25/. Accessed on 01 November, 2020.

Cite this article as: Bagdi P, S N. Appendicular endometriosis: a case report. Int J Reprod Contracept Obstet Gynecol 2021;10:794-6. 